medRxiv preprint doi: https://doi.org/10.1101/2021.05.18.21257369; this version posted May 19, 2021. The copyright holder for this preprint

(which was not certified by peer review) is the author/funder, who has granted medRxiv a license to display the preprint in perpetuity.

It is made available under a CC-BY-NC-ND 4.0 International license .

\title{
Predicting bloodstream infection outcome using machine learning
}

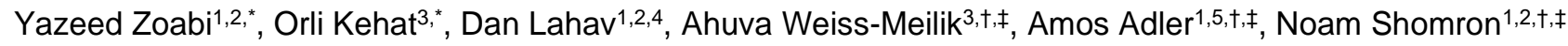

${ }^{1}$ Sackler Faculty of Medicine, Tel Aviv University, Tel Aviv, 6997801, Israel

2Edmond J Safra Center for Bioinformatics, Tel Aviv University, Tel Aviv, 6997801, Israel

3l-Medata Al Center, Tel-Aviv Sourasky Medical Center, Tel Aviv, 6423906, Israel

${ }^{4}$ The Blavatnik School of Computer Science, Tel Aviv University, Tel Aviv 6997801, Israel

${ }^{5}$ Clinical Microbiology Laboratory, Tel Aviv Sourasky Medical Center, Tel Aviv, 6423906, Israel

${ }^{*}$ These authors are equal contributors to this study.

†These authors are equal contributors to this study.

$\ddagger$ Correspondence should be addressed to:

AA amosa@tlvmc.gov.il

AWM ahuvawm@tlvmc.gov.il

NS nshomron@tauex.tau.ac.il 
medRxiv preprint doi: https://doi.org/10.1101/2021.05.18.21257369; this version posted May 19, 2021. The copyright holder for this preprint (which was not certified by peer review) is the author/funder, who has granted medRxiv a license to display the preprint in perpetuity. It is made available under a CC-BY-NC-ND 4.0 International license .

\section{Abstract}

Bloodstream infections (BSI) are a main cause of infectious disease morbidity and mortality worldwide. Early prediction of patients at high risk of poor outcomes of BSI is important for earlier decision making and effective patient stratification. We developed electronic medical record-based machine learning models that predict patient outcomes of BSI. The area under the receiver-operating characteristics curve was 0.82 for a full featured inclusive model, and 0.81 for a compact model using only 25 features. Our models were trained, using electronic medical records that include demographics, blood tests, and the medical and diagnosis history of 7,889 hospitalized patients diagnosed with BSI. Among the implications of this work is implementation of the models as a basis for selective rapid microbiological identification, toward earlier administration of appropriate antibiotic therapy. Additionally, our models may help reduce the development of BSI and its associated adverse health outcomes and complications. 
medRxiv preprint doi: https://doi.org/10.1101/2021.05.18.21257369; this version posted May 19, 2021. The copyright holder for this preprint

(which was not certified by peer review) is the author/funder, who has granted medRxiv a license to display the preprint in perpetuity.

It is made available under a CC-BY-NC-ND 4.0 International license.

\section{Introduction}

Bloodstream infections (BSI) can lead to prolonged hospital stays, and life-threatening and aggressive complications, in addition to high costs to health care systems [1-4]. Increasing rates of antimicrobialresistant pathogens, particularly gram-negative bacteria, limit treatment options; this often prompts empirical use of broad-range antibiotics [5]. Therefore, timely and critical assessment of available microbiology results are necessary to ensure that individuals with BSI receive prompt, effective, and targeted treatment, for optimal clinical outcomes [5]. However, the current standard-of-care, which mostly depends on blood culture-based diagnosis, is often extremely slow [6].

Sepsis is a life-threatening medical condition, defined as the body's systemic immunological response to an infectious process, which may cause end-stage organ dysfunction and eventually death [7]. Several studies have utilized electronic medical records (EMRs) to construct prediction models for mortality from sepsis $[8,9]$ and sepsis onset [12-15]. From a clinical perspective, these types of early warning systems may be useful in detecting patients at risk of BSI, and typically provide information at a certain point in time (for example, preoperatively [16]) or in a certain time-window before deterioration (see review in [17]). Identifying a patient at risk can trigger early goal-directed therapy regarding confirmation of infection, administration of antimicrobial therapy, and transition to the intensive care unit (ICU).

In contrast to studies that aimed to detect patients at risk of BSI, the current study focused on patients with confirmed infections. Based on EMRs of patients hospitalized with positive blood cultures, we constructed machine learning models that predict poor outcomes of hospitalized patients with BSI (Fig. 1; see Methods). Our prediction occurs at a certain point of time: just after the identification of bacterial 
medRxiv preprint doi: https://doi.org/10.1101/2021.05.18.21257369; this version posted May 19, 2021. The copyright holder for this preprint (which was not certified by peer review) is the author/funder, who has granted medRxiv a license to display the preprint in perpetuity.

It is made available under a CC-BY-NC-ND 4.0 International license.

morphology on direct gram stain from a positive blood culture, yet well before performing specific pathogen identification. At this point of time, early goal-directed clinical practice can be diverted to patients at risk for poor clinical outcomes. In addition, the prediction can facilitate deciding at the microbiology lab, between using the traditional lengthy pathogen identification routine or rapid microbiological identification techniques [18]. A forewarning system could direct the required resources to the patients with BSI in the greatest need.

\section{Results}

\section{The inclusive model}

The characteristics of the population used for the training and testing of the inclusive model are described in Table 1 (see Methods). From 7,889 adults with a BSI, 2,590 (32.8\%) positive composite outcomes were recorded. The contribution of each feature of the inclusive model to predict the composite outcome was measured by SHaply Additive exPlanations (SHAP) scores, for each patient (Fig. 2). The predictive contribution of missingness (gray points) was also assessed. Accordingly, a missing value of a feature (e.g., albumin) serves as a signal regarding the patient's risk. SHAP values of three selected variables - age, monocyte \%, albumin - are presented in Fig. $2 b-d$. The top 20 features ranked by the SHAP scores were also calculated (see Supplementary Fig. 1). The calibrated model was tested on a subset of the future test set, which comprised only patients in the ICU (the results are presented in Supplementary Fig. 2).

Performance of the inclusive prediction model on the test set showed area under the receiver-operating characteristics curve (auROC) of 0.82 (95\% confidence intervals (CI): 0.80-0.845), which indicates good discrimination; and an area under the precision-recall curve (auPRC) of 0.65 (95\% CI: 0.61- 
medRxiv preprint doi: https://doi.org/10.1101/2021.05.18.21257369; this version posted May 19, 2021. The copyright holder for this preprint

(which was not certified by peer review) is the author/funder, who has granted medRxiv a license to display the preprint in perpetuity.

It is made available under a CC-BY-NC-ND 4.0 International license .

0.70) (Fig. 3). The calibration plot, which runs very close to the diagonal, shows excellent calibration (Fig. 3c).

\section{The compact model}

The numerous EMR features, more than 600, incorporated in the inclusive model render its external validation and the reproducibility of results very difficult. This limits its applicability to other hospitals. Hence, we established a simpler and more compact prediction model that incorporates the features with the greatest impact on outcome, and that are most commonly listed in EMR datasets from other hospitals. To this end, we trained and evaluated the performance of a compact model with only 25 features, including simple demographic information, a single blood test, and a brief medical history

(Fig. 4.d). We used the same cohort of patients of the training and test sets from the previous analysis (see the inclusive model). The compact model achieves an auROC of 0.81 and auPRC of 0.63 (Fig. 4.a and Fig. 4.b), which is only slightly lower than the values of the inclusive model, with good calibration (Fig. 4.c). SHAP scores are shown in Figure 5.

The code to test this model is available in our GitHub repository.

\section{Discussion}

In this study, we examined the ability to utilize EMRs to predict a composite poor outcome of patients with BSI, which may promote both rapid interventions and patient stratification. Several scoring systems have been developed in recent years for stratifying the risk of patients with sepsis $[8,12-15,17]$, but not for outcomes of patients with BSI. In addition, none are commonly used in routine practice nor recommended according to current guidelines. 
medRxiv preprint doi: https://doi.org/10.1101/2021.05.18.21257369; this version posted May 19, 2021. The copyright holder for this preprint (which was not certified by peer review) is the author/funder, who has granted medRxiv a license to display the preprint in perpetuity. It is made available under a CC-BY-NC-ND 4.0 International license.

Our results show that EMRs can be used to produce accurate predictions of BSI outcomes. Our retrospective analysis demonstrates the feasibility of accurate prediction of BSI outcomes using data available in EMRs. In the inclusive model, the prediction was after a gram-stain, and yielded an auROC of 0.82 , and an auPRC of 0.65 . In the compact model, the prediction was based on only 25 features available at the time of culture, not including gram-stain results; and yielded an auROC of 0.81 , and an auPRC of 0.63. In addition to the well-established risk factors for complications from BSI, such as age and previous infections, our analysis revealed less-known factors as highly predictive of a poor outcome from BSIs. The main factors that were identified as increasing risk included: red cell distribution width, albumin, and creatinine. Red cell distribution width and albumin have been associated with mortality, and have been used as prognostic markers in a number of studies [19-26]. The Charlson Comorbidity Index has also been found to predict mortality in various medical situations [27, 28]. However, other factors revealed as central by our analysis, such as serum creatinine values and monocyte counts, are less well recognized and used as predictors of a poor outcome in patients with BSI.

Although maximal model explainability requires using the patient's entire EMR, we demonstrated that a subset of features, available from only simple demographic information and a single blood test, enables accurate prediction with only a slight decrease in auROC, from 0.82 in the inclusive model to 0.81 in the compact model. This may enable accurate BSI outcome estimation by embedded systems in emergency departments of hospitals.

Our work has several clinical applications. For instance, it can help select individuals at high-risk for BSI, for whom hospitalization in the ICU, treatment with broad-spectrum antibiotics, or effective earlystage rapid microbiological identification should be considered. 
medRxiv preprint doi: https://doi.org/10.1101/2021.05.18.21257369; this version posted May 19, 2021. The copyright holder for this preprint (which was not certified by peer review) is the author/funder, who has granted medRxiv a license to display the preprint in perpetuity. It is made available under a CC-BY-NC-ND 4.0 International license.

The benefit of early microbiological identification for patient outcomes has been well described in the medical literature [5, 29] and the time-to-administration of appropriate antibiotics to treat BSI is an important predictor of outcomes [30]. The current study therefore paves the route for future randomized control trials to further study the effectiveness of implementing a model for early prediction of BSI outcomes, possible preventive interventions, and more efficient selection of patients for advanced microbiological diagnostic testing, thus reducing the time-to-administration of appropriate antibiotics.

Our study has several limitations. First, our prediction model is based on retrospective EMR data, which have inherent biases and are influenced by the interaction of the patient with the health system [31]. However, these biases are partially mitigated in this study, since the data contain information originating from a public hospital serving a very large population, and since the outcome of the model is based on information that is accurately and comprehensively documented in the EMRs. Another limitation of the study is that we assessed BSI outcomes only in patients who were already diagnosed with BSI (having a positive blood culture). This makes it more difficult to generalize to the entire emergency room population. Finally, the predictor was trained and validated on EMRs from Tel Aviv Sourasky Medical Center (TASMC), composed of patients from and around Tel Aviv, Israel. Nonetheless, TASMC is a public hospital, and the medical system in Israel is accessible to the entire population.

Applicability of the model to other hospital populations needs to be shown. However, the large size of the data, and the comprehensive validation process and its result, namely, validation of the utility of 
medRxiv preprint doi: https://doi.org/10.1101/2021.05.18.21257369; this version posted May 19, 2021. The copyright holder for this preprint (which was not certified by peer review) is the author/funder, who has granted medRxiv a license to display the preprint in perpetuity.

It is made available under a CC-BY-NC-ND 4.0 International license .

established risk factors for a poor BSI outcome, all support the model's generalizability to other hospitals. Given the additional complexities introduced by the machine learning algorithms, we sought to ensure that sufficient information would be provided to enable our model to undergo external validation $[32,33]$. This drove us to develop the compact model, which is based on the features with the greatest influence on the overall prediction, and that are easily accessible in EMR datasets from other hospitals. This compact model achieved only a slightly reduced auROC of 0.81 . We made the compact model available in our GitHub repository (see code availability) and we encourage researchers with similar data from other hospitals to test it.

In conclusion, our work demonstrates that accurate and calibrated predictions of BSI outcomes early in a hospital admission can be achieved. Earlier and better characterization of patients with BSI could potentially reduce the development of BSI and its associated adverse health outcomes and complications. Our predictive model could become the basis of selective, rapid microbiological identification, and also contribute to various decisions such as ICU hospitalization and administration of broad-spectrum antibiotics. Future prospective studies, as well as those on populations from other hospitals, are needed to evaluate the clinical impact of the model.

\section{Methods}

\section{Study design, population, and definition of outcome}

The study was designed as a retrospective cohort study for the development and validation of a clinical prediction model. The study was performed at the TASMC, a 1,500-bed public tertiary care center, and the only general hospital serving the population of Tel-Aviv, the most populous city in Israel, of 
medRxiv preprint doi: https://doi.org/10.1101/2021.05.18.21257369; this version posted May 19, 2021. The copyright holder for this preprint (which was not certified by peer review) is the author/funder, who has granted medRxiv a license to display the preprint in perpetuity. It is made available under a CC-BY-NC-ND 4.0 International license.

all socioeconomic backgrounds. Data processing, model training and analyses were performed at the TASMC Data Science Department and the Faculty of Medicine at Tel Aviv University.

The study included EMRs of adults hospitalized with a positive blood culture (bacterial only) in the period between January 2014 and January 2020. The year 2014 was determined as the starting point since frequent changes in variable identifiers occurred in the preceding years. Patients' EMRs included demographics, laboratory test results, previous diagnoses recorded at TASMC, recorded medical history, and initial gram-stain morphology of positive blood cultures that are reported by phone.

The models were developed according to features extracted from various modalities available in EMRs of patients hospitalized with a positive blood culture at the TASMC, and predicted a composite poor outcome, defined as at least one of the following:

- Short term in-hospital mortality within 10 days of a culture.

- Mechanical ventilation in the 10 days after the culture.

- $\quad$ Prolonged length of stay (>6 weeks).

The study flow chart is presented in Fig. 1. Exclusion criteria were: the absence of laboratory data of medical history information, age younger than 18 years or older than 100 years, and patients' explicit objection to the use of their medical data for research purposes. Before initiating any analysis, the study population was divided into a training set that included 6,434 admissions (from years 2014-2018) and a validation set that included 1,455 admissions during 2019 and the first month of 2020. The model was also validated on two subsets of the validation set, which comprised only patients from ICUs or 
medRxiv preprint doi: https://doi.org/10.1101/2021.05.18.21257369; this version posted May 19, 2021. The copyright holder for this preprint (which was not certified by peer review) is the author/funder, who has granted medRxiv a license to display the preprint in perpetuity.

It is made available under a CC-BY-NC-ND 4.0 International license.

only patients from the emergency room. Both these subsets posed a high challenge to the model regarding its generalization. The prospective validation cross-sections were performed to emulate the model's use in practice and in real world situations.

\section{Variable and feature selection}

To evaluate whether EMR-derived information might accurately predict outcomes of patients with BSI, we compiled a set of 606 features. All these features were available at the time a blood sample was sent for culture, except for the gram-stain information (used only in the inclusive model). With all these features, we trained a gradient-boosting model, the inclusive model, to predict the probability that each held-out sample (patients not included in the training set) would have a poor outcome. Distributions of the various modalities of the features used are depicted in Fig. 1b. In addition, we trained and tested a compact model, comprising 25 features, for application on EMRs from other hospitals.

Each of the 606 features was assigned a category. For more comprehensive representation, some features within a category were combined, such that all the features could be represented using 96 variables. These variables were used to create the pie chart in Fig 1.b. The following list describes the mechanism for generating the features, and for grouping them:

(A) Demographics (238 features, 14 variables when grouped)

- Contains features such as age, sex, and number of children. A total of 228 categorical features, which included birth country and nationality, were grouped to five variables.

(B) History (108 features, 14 when grouped)

- Contains medical history that is not documented as diagnosis history. This includes unit information (ICU, emergency room, etc.), surgery information, and chest pain. A total of 97 categorical features were grouped to three variables. 
medRxiv preprint doi: https://doi.org/10.1101/2021.05.18.21257369; this version posted May 19, 2021. The copyright holder for this preprint (which was not certified by peer review) is the author/funder, who has granted medRxiv a license to display the preprint in perpetuity. It is made available under a CC-BY-NC-ND 4.0 International license .

(C) Medications (five features)

- Contains binary information about five medications: general diabetes drugs, insulin, anti-coagulants, anti-aggregants, and coumadin on admission.

(D) Laboratory (33 features, 30 when grouped)

- Contains laboratory test results. Four categorical features, describing gram staining results, were combined into one variable. All other features in this category had continuous numeric values.

(E) Diagnoses (222 features, 33 when grouped)

- Diagnoses history is recorded in TASMC as ICD-9 codes. The ICD-9 code hierarchy was used to group these features into 33 variables represented by ICD-9 codes of higher hierarchy.

\section{Analysis platform}

All computational analyses were performed on a secure compute cluster environment located at TASMC. Python 3, with numpy, pandas, and scikit-learn formed the backbone of the data-processing pipeline.

\section{Development of the models}

Predictions were generated using a gradient-boosting machine model built with decision-tree baselearners [34]. Such models have demonstrated efficacy in prediction, using tabular data [35], and have been incorporated in several successful algorithms in the field of machine learning [36]. We implemented the gradient-boosting predictor trained with the LightGBM [37] Python package. LightGBM has shown effectiveness on clinical and patient tabular data in particular, and was adopted by many recently published models [38-43]. Missing values were inherently handled by the LightGBM predictor $[37,44,45]$. The validation set was used for early stopping [46], with auROC as the performance 
medRxiv preprint doi: https://doi.org/10.1101/2021.05.18.21257369; this version posted May 19, 2021. The copyright holder for this preprint (which was not certified by peer review) is the author/funder, who has granted medRxiv a license to display the preprint in perpetuity.

It is made available under a CC-BY-NC-ND 4.0 International license.

measure. The hyperparameters used are available at our GitHub repository. Two LightGBM classifiers with differing complexity were developed: the inclusive and compact models. The compact model is available at our GitHub repository (see Code Availability).

\section{The mechanistic basis of the models}

To identify the principal features driving model prediction, SHAP values [47] were calculated. These values are suited for complex models such as artificial neural networks and gradient-boosting machines [48]. Originating in game theory, SHAP values partition the prediction result of every sample into the contribution of each constituent feature value. This is done by estimating differences between models with subsets of the feature space. By averaging across samples, SHAP values estimate the contribution of each feature to overall model predictions. A higher value indicates that a feature has a larger impact on the model, which indicates that the feature is more important.

\section{Calibration of the models}

We analyzed the calibration (observed risk versus raw prediction score) of our proposed inclusive and compact models. The raw prediction scores produced by the machine learning model (LightGBM) were calibrated and evaluated on the test-set. We used isotonic regression, which fits a rank-preserving transformation between the original scores and transformed scores; and minimizes the deviation between the target label and the prediction score. We used the scikit-learn library (version 0.20.0) for fitting the isotonic regression model. Ten prediction score bins were used, with regular spacing between the minimum/maximum prediction score produced by a model. We noticed that the raw scores were already well-calibrated. Curves for isotonic and sigmoid calibrations, as well as for the raw model are presented in Figure 6.

\section{Evaluation of the models}


medRxiv preprint doi: https://doi.org/10.1101/2021.05.18.21257369; this version posted May 19, 2021. The copyright holder for this preprint (which was not certified by peer review) is the author/funder, who has granted medRxiv a license to display the preprint in perpetuity. It is made available under a CC-BY-NC-ND 4.0 International license .

The models were scored on the test set using the auROC. In addition, plots of positive predictive value (PPV) against sensitivity (precision-recall curve) were drawn across different thresholds. For all the thresholds from all the ROC curves, metrics were calculated, including sensitivity, specificity, PPV, negative predictive value, false positive rate, false negative rate, false discovery rate, and overall accuracy (Supplementary Dataset 1). Confidence intervals for the various performance measures were derived through resampling, using the bootstrap percentile method [49] with 1,000 repetitions.

\section{Ethics declarations}

This study (TLV-0684-18) was approved by the TASMC Institutional Review Board (IRB). All methods were performed in accordance with the IRB policy, guidelines, and regulations. Informed consent was waived by the IRB, as all identifying details of the participants were removed before any computational analysis.

\section{Data Availability statement}

The data that support the findings of this study are from TASMC. Access restrictions apply to these data and they are therefore not publicly available. Due to these restrictions, these data can be accessed only by request to TASMC or the authors.

\section{Code Availability statement}

Hyperparameters for the models and the analytic code of the compact model are available at: https://github.com/nshomron/infecpred.

\section{Acknowledgements}

Y.Z. and D.L. are partially supported by the Edmond J. Safra Center for Bioinformatics at Tel-Aviv University. The Shomron lab is partially supported by the Adelis Foundation. 
medRxiv preprint doi: https://doi.org/10.1101/2021.05.18.21257369; this version posted May 19, 2021. The copyright holder for this preprint (which was not certified by peer review) is the author/funder, who has granted medRxiv a license to display the preprint in perpetuity. It is made available under a CC-BY-NC-ND 4.0 International license .

\section{Author Contribution}

Y.Z., O.K., A.WM., A.A., N.S. designed the study and wrote the paper. Y.Z. developed the models. O.K. collected the data. Y.Z. and O.K. did the statistical analysis. D.L. contributed to the development of the compact model.

\section{Competing Interests}

There are no competing interests. 
medRxiv preprint doi: https://doi.org/10.1101/2021.05.18.21257369; this version posted May 19, 2021. The copyright holder for this preprint (which was not certified by peer review) is the author/funder, who has granted medRxiv a license to display the preprint in perpetuity. It is made available under a CC-BY-NC-ND 4.0 International license.

\section{References}

1. Goto M, Al-Hasan MN (2013) Overall burden of bloodstream infection and nosocomial bloodstream infection in North America and Europe. Clinical Microbiology and Infection 19:501-509. https://doi.org/10.1111/1469-0691.12195

2. Pittet D, Tarara D, Wenzel RP (1994) Nosocomial Bloodstream Infection in Critically III Patients: Excess Length of Stay, Extra Costs, and Attributable Mortality. JAMA 271:1598-1601. https://doi.org/10.1001/jama.1994.03510440058033

3. Rudd KE, Johnson SC, Agesa KM, et al (2020) Global, regional, and national sepsis incidence and mortality, 1990-2017: analysis for the Global Burden of Disease Study. The Lancet 395:200-211. https://doi.org/10.1016/S0140-6736(19)32989-7

4. Angus DC, Linde-Zwirble WT, Lidicker J, et al (2001) Epidemiology of severe sepsis in the United States: Analysis of incidence, outcome, and associated costs of care. Critical Care Medicine 29:1303-1310

5. Seymour CW, Gesten F, Prescott HC, et al (2017) Time to Treatment and Mortality during Mandated Emergency Care for Sepsis. New England Journal of Medicine 376:2235-2244. https://doi.org/10.1056/NEJMoa1703058

6. MacVane SH, Nolte FS (2016) Benefits of Adding a Rapid PCR-Based Blood Culture Identification Panel to an Established Antimicrobial Stewardship Program. Journal of Clinical Microbiology 54:2455-2463. https://doi.org/10.1128/JCM.00996-16

7. Gyawali B, Ramakrishna K, Dhamoon AS (2019) Sepsis: The evolution in definition, pathophysiology, and management. SAGE Open Medicine 7:. https://doi.org/10.1177/2050312119835043 
medRxiv preprint doi: https://doi.org/10.1101/2021.05.18.21257369; this version posted May 19, 2021. The copyright holder for this preprint (which was not certified by peer review) is the author/funder, who has granted medRxiv a license to display the preprint in perpetuity. It is made available under a CC-BY-NC-ND 4.0 International license.

8. Taylor RA, Pare JR, Venkatesh AK, et al (2016) Prediction of In-hospital Mortality in Emergency Department Patients With Sepsis: A Local Big Data-Driven, Machine Learning Approach. Academic Emergency Medicine 23:269-278. https://doi.org/10.1111/acem.12876

9. Gultepe E, Green JP, Nguyen H, et al (2014) From vital signs to clinical outcomes for patients with sepsis: a machine learning basis for a clinical decision support system. Journal of the American Medical Informatics Association 21:315-325. https://doi.org/10.1136/amiajnl-2013-001815

10. Avati A, Jung K, Harman S, et al (2018) Improving palliative care with deep learning. BMC Medical Informatics and Decision Making 18:122. https://doi.org/10.1186/s12911-018-0677-8

11. Silva I, Moody G, Scott DJ, et al (2012) Predicting in-hospital mortality of ICU patients: The PhysioNet/Computing in cardiology challenge 2012. In: 2012 Computing in Cardiology. pp 245248

12. Nemati S, Holder A, Razmi F, et al (2018) An Interpretable Machine Learning Model for Accurate Prediction of Sepsis in the ICU. Crit Care Med 46:547-553. https://doi.org/10.1097/CCM.0000000000002936

13. Islam MdM, Nasrin T, Walther BA, et al (2019) Prediction of sepsis patients using machine learning approach: A meta-analysis. Computer Methods and Programs in Biomedicine 170:1-9. https://doi.org/10.1016/j.cmpb.2018.12.027

14. Delahanty RJ, Alvarez J, Flynn LM, et al (2019) Development and Evaluation of a Machine Learning Model for the Early Identification of Patients at Risk for Sepsis. Ann Emerg Med 73:334-344. https://doi.org/10.1016/j.annemergmed.2018.11.036 
medRxiv preprint doi: https://doi.org/10.1101/2021.05.18.21257369; this version posted May 19, 2021. The copyright holder for this preprint (which was not certified by peer review) is the author/funder, who has granted medRxiv a license to display the preprint in perpetuity. It is made available under a CC-BY-NC-ND 4.0 International license.

15. Desautels T, Calvert J, Hoffman J, et al (2016) Prediction of Sepsis in the Intensive Care Unit With Minimal Electronic Health Record Data: A Machine Learning Approach. JMIR Medical Informatics 4:e5909. https://doi.org/10.2196/medinform.5909

16. Thottakkara P, Ozrazgat-Baslanti T, Hupf BB, et al (2016) Application of Machine Learning Techniques to High-Dimensional Clinical Data to Forecast Postoperative Complications. PLOS ONE 11:e0155705. https://doi.org/10.1371/journal.pone.0155705

17. Fleuren LM, Klausch TLT, Zwager CL, et al (2020) Machine learning for the prediction of sepsis: a systematic review and meta-analysis of diagnostic test accuracy. Intensive Care Med 46:383400. https://doi.org/10.1007/s00134-019-05872-y

18. Caliendo AM, Gilbert DN, Ginocchio CC, et al (2013) Better tests, better care: improved diagnostics for infectious diseases. Clin Infect Dis 57 Suppl 3:S139-170. https://doi.org/10.1093/cid/cit578

19. Yoo J-W, Ju S, Lee SJ, et al (2020) Red cell distribution width/albumin ratio is associated with 60day mortality in patients with acute respiratory distress syndrome. Infectious Diseases 52:266270. https://doi.org/10.1080/23744235.2020.1717599

20. Zhang Z, Xu X, Ni H, Deng H (2013) Red cell distribution width is associated with hospital mortality in unselected critically ill patients. $J$ Thorac Dis 5:730-736. https://doi.org/10.3978/j.issn.2072-1439.2013.11.14

21. Patel KV, Ferrucci L, Ershler WB, et al (2009) Red Blood Cell Distribution Width and the Risk of Death in Middle-aged and Older Adults. Arch Intern Med 169:515. https://doi.org/10.1001/archinternmed.2009.11 
medRxiv preprint doi: https://doi.org/10.1101/2021.05.18.21257369; this version posted May 19, 2021. The copyright holder for this preprint

(which was not certified by peer review) is the author/funder, who has granted medRxiv a license to display the preprint in perpetuity.

It is made available under a CC-BY-NC-ND 4.0 International license .

22. Chen L, Lu XY, Zhu CQ (2020) Prognostic value of albumin-red cell distribution width score in patients with severe community-acquired pneumonia. Annals of Palliative Medicine 9:7596575765. https://doi.org/10.21037/apm.2020.04.22

23. Lee JH, Chung HJ, Kim K, et al (2013) Red cell distribution width as a prognostic marker in patients with community-acquired pneumonia. The American Journal of Emergency Medicine 31:72-79. https://doi.org/10.1016/j.ajem.2012.06.004

24. Hannan JL, Radwany SM, Albanese T (2012) In-Hospital Mortality in Patients Older Than 60 Years with Very Low Albumin Levels. Journal of Pain and Symptom Management 43:631-637. https://doi.org/10.1016/j.jpainsymman.2011.04.009

25. Akirov A, Masri-Iraqi H, Atamna A, Shimon I (2017) Low Albumin Levels Are Associated with Mortality Risk in Hospitalized Patients. The American Journal of Medicine 130:1465.e111465.e19. https://doi.org/10.1016/j.amjmed.2017.07.020

26. Goldwasser P, Feldman J (1997) Association of serum albumin and mortality risk. J Clin Epidemiol 50:693-703. https://doi.org/10.1016/s0895-4356(97)00015-2

27. Bannay A, Chaignot C, Blotiere P-O, et al (2016) The Best Use of the Charlson Comorbidity Index With Electronic Health Care Database to Predict Mortality. Medical Care 54:188. https://doi.org/10.1097/MLR.0000000000000471

28. Huang Y, Gou R, Diao Y, et al (2014) Charlson comorbidity index helps predict the risk of mortality for patients with type 2 diabetic nephropathy. J Zhejiang Univ Sci B 15:58-66. https://doi.org/10.1631/jzus.B1300109 
medRxiv preprint doi: https://doi.org/10.1101/2021.05.18.21257369; this version posted May 19, 2021. The copyright holder for this preprint (which was not certified by peer review) is the author/funder, who has granted medRxiv a license to display the preprint in perpetuity. It is made available under a CC-BY-NC-ND 4.0 International license.

29. Bernhard M, Lichtenstern C, Eckmann C, Weigand MA (2014) The early antibiotic therapy in septic patients - milestone or sticking point? Critical Care 18:671. https://doi.org/10.1186/s13054014-0671-1

30. Falcone M, Bassetti M, Tiseo G, et al (2020) Time to appropriate antibiotic therapy is a predictor of outcome in patients with bloodstream infection caused by KPC-producing Klebsiella pneumoniae. Critical Care 24:29. https://doi.org/10.1186/s13054-020-2742-9

31. Phelan M, Bhavsar NA, Goldstein BA Illustrating Informed Presence Bias in Electronic Health Records Data: How Patient Interactions with a Health System Can Impact Inference. EGEMS (Wash DC) 5:. https://doi.org/10.5334/egems.243

32. Dagan N, Cohen-Stavi C, Leventer-Roberts M, Balicer RD (2017) External validation and comparison of three prediction tools for risk of osteoporotic fractures using data from population based electronic health records: retrospective cohort study. BMJ 356:i6755. https://doi.org/10.1136/bmj.i6755

33. Vollmer S, Mateen BA, Bohner G, et al (2020) Machine learning and artificial intelligence research for patient benefit: 20 critical questions on transparency, replicability, ethics, and effectiveness. BMJ 368:16927. https://doi.org/10.1136/bmj.16927

34. Hastie T, Tibshirani R, Friedman J (2009) Boosting and Additive Trees. In: Hastie T, Tibshirani R, Friedman J (eds) The Elements of Statistical Learning: Data Mining, Inference, and Prediction. Springer, New York, NY, pp 337-387 
medRxiv preprint doi: https://doi.org/10.1101/2021.05.18.21257369; this version posted May 19, 2021. The copyright holder for this preprint

(which was not certified by peer review) is the author/funder, who has granted medRxiv a license to display the preprint in perpetuity.

It is made available under a CC-BY-NC-ND 4.0 International license.

35. Fernández-Delgado M, Cernadas E, Barro S, Amorim D (2014) Do we Need Hundreds of Classifiers to Solve Real World Classification Problems? Journal of Machine Learning Research $15: 3133-3181$

36. Omar KBA (2018) XGBoost and LGBM for Porto Seguro's Kaggle challenge : A comparison Semester Project

37. Ke G, Meng Q, Finley T, et al (2017) LightGBM: A Highly Efficient Gradient Boosting Decision Tree. In: Guyon I, Luxburg UV, Bengio S, et al (eds) Advances in Neural Information Processing Systems 30. Curran Associates, Inc., pp 3146-3154

38. Wang T, Liu G, Lin H (2020) A machine learning approach to predict intravenous immunoglobulin resistance in Kawasaki disease patients: A study based on a Southeast China population. PLOS ONE 15:e0237321. https://doi.org/10.1371/journal.pone.0237321

39. Zoabi Y, Deri-Rozov S, Shomron N (2021) Machine learning-based prediction of COVID-19 diagnosis based on symptoms. npj Digital Medicine 4:1-5. https://doi.org/10.1038/s41746-02000372-6

40. Artzi NS, Shilo S, Hadar E, et al (2020) Prediction of gestational diabetes based on nationwide electronic health records. Nature Medicine 26:71-76. https://doi.org/10.1038/s41591-019-0724-8

41. Kopitar L, Kocbek P, Cilar L, et al (2020) Early detection of type 2 diabetes mellitus using machine learning-based prediction models. Scientific Reports 10:11981. https://doi.org/10.1038/s41598020-68771-z 
medRxiv preprint doi: https://doi.org/10.1101/2021.05.18.21257369; this version posted May 19, 2021. The copyright holder for this preprint (which was not certified by peer review) is the author/funder, who has granted medRxiv a license to display the preprint in perpetuity. It is made available under a CC-BY-NC-ND 4.0 International license.

42. Shin Y, Kim S, Chung J, et al (2020) Emergency Department Return Prediction System using Blood Samples with LightGBM for Smart Health Care Services. IEEE Consumer Electronics Magazine 1-1. https://doi.org/10.1109/MCE.2020.3015439

43. Razavian N, Major VJ, Sudarshan M, et al (2020) A validated, real-time prediction model for favorable outcomes in hospitalized COVID-19 patients. npj Digital Medicine 3:1-13. https://doi.org/10.1038/s41746-020-00343-X

44. Josse J, Prost N, Scornet E, Varoquaux G (2019) On the consistency of supervised learning with missing values. arXiv:190206931 [cs, math, stat]

45. Chen T, Guestrin C (2016) XGBoost: A Scalable Tree Boosting System. In: Proceedings of the 22nd ACM SIGKDD International Conference on Knowledge Discovery and Data Mining. Association for Computing Machinery, San Francisco, California, USA, pp 785-794

46. Raskutti G, Wainwright MJ, Yu B (2011) Early stopping for non-parametric regression: An optimal data-dependent stopping rule. In: 2011 49th Annual Allerton Conference on Communication, Control, and Computing (Allerton). pp 1318-1325

47. Lundberg S, Lee S-I (2017) A Unified Approach to Interpreting Model Predictions. arXiv:170507874 [cs, stat]

48. Lundberg SM, Nair B, Vavilala MS, et al (2018) Explainable machine-learning predictions for the prevention of hypoxaemia during surgery. Nature Biomedical Engineering 2:749-760. https://doi.org/10.1038/s41551-018-0304-0

49. Efron B, Tibshirani RJ (1994) An introduction to the bootstrap. CRC press 


\section{Figures and Legends}

a

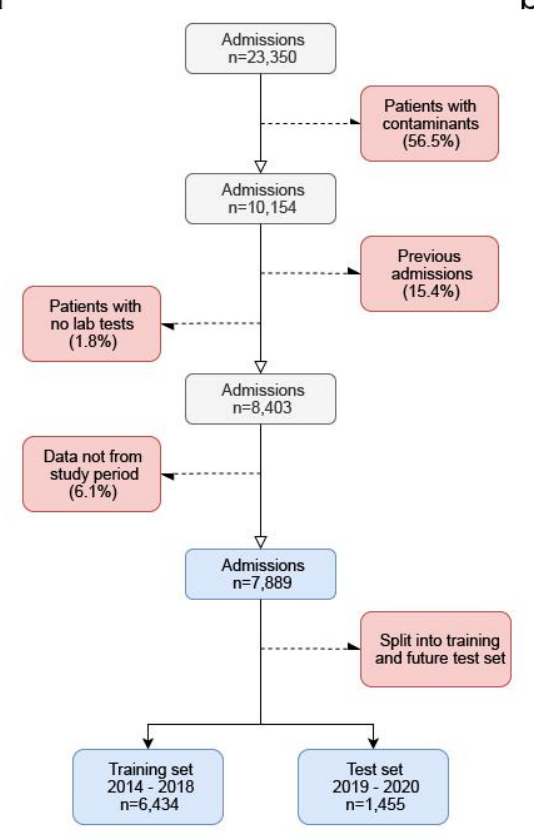

b

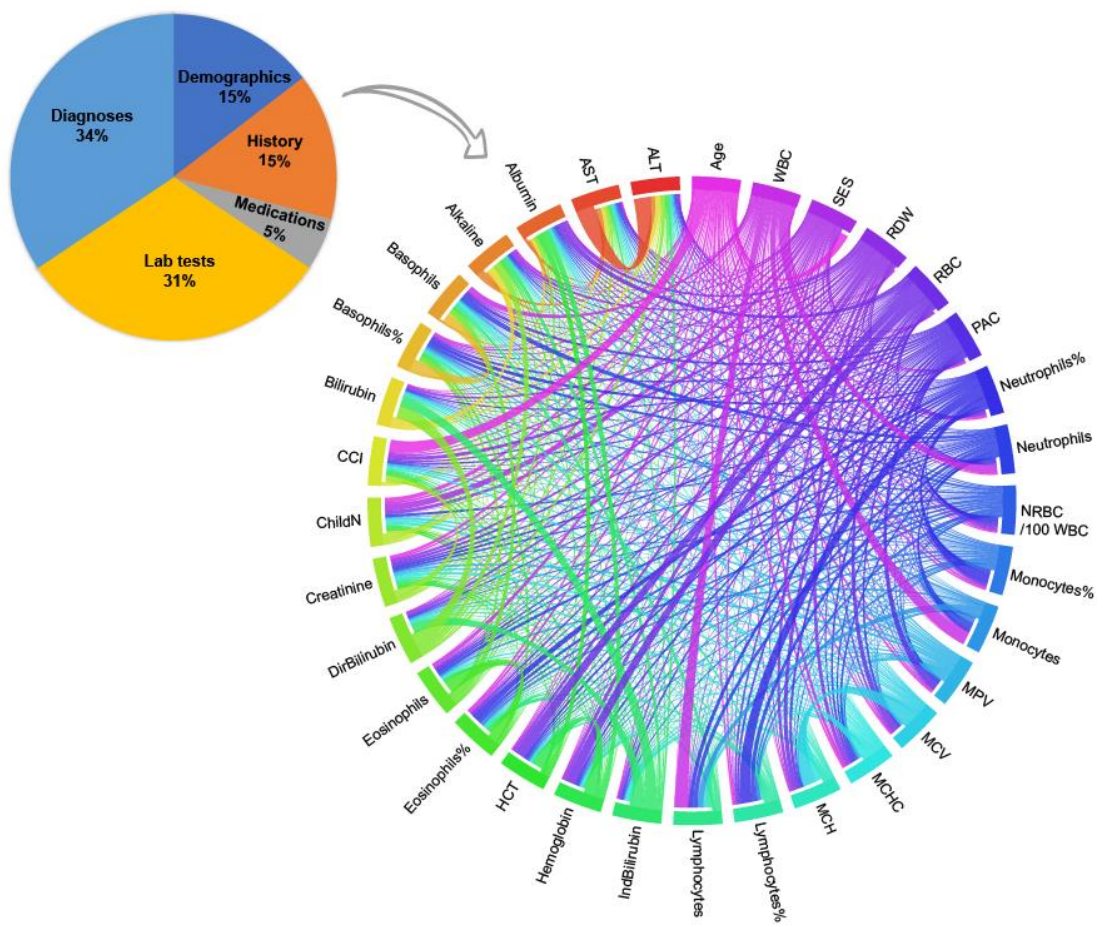

Figure 1, Data and cohort characteristics. a, Cohort selection. Bloodstream infection was identified as a positive culture test. Next, patients with only contaminants were excluded (a list of bacteria classified as contaminants is available in the supplementary information). Subsequently, previous admissions for each patient and patients with no lab tests information were excluded. Finally, the cohort was divided into training and validation sets (see Methods). b, Feature modality distribution. Pie charts are divided according to the sum of data points in each feature set. A substantial proportion of the data originates from laboratory test results during current or previous admissions. The Circos plot shows the correlation between continuous features from the entire cohort (test and training sets). Correlation strength is determined by Pearson correlation, thicker bands correspond to a stronger Pearson correlation coefficient. 
medRxiv preprint doi: https://doi.org/10.1101/2021.05.18.21257369; this version posted May 19, 2021. The copyright holder for this preprint (which was not certified by peer review) is the author/funder, who has granted medRxiv a license to display the preprint in perpetuity.

It is made available under a CC-BY-NC-ND 4.0 International license.

a

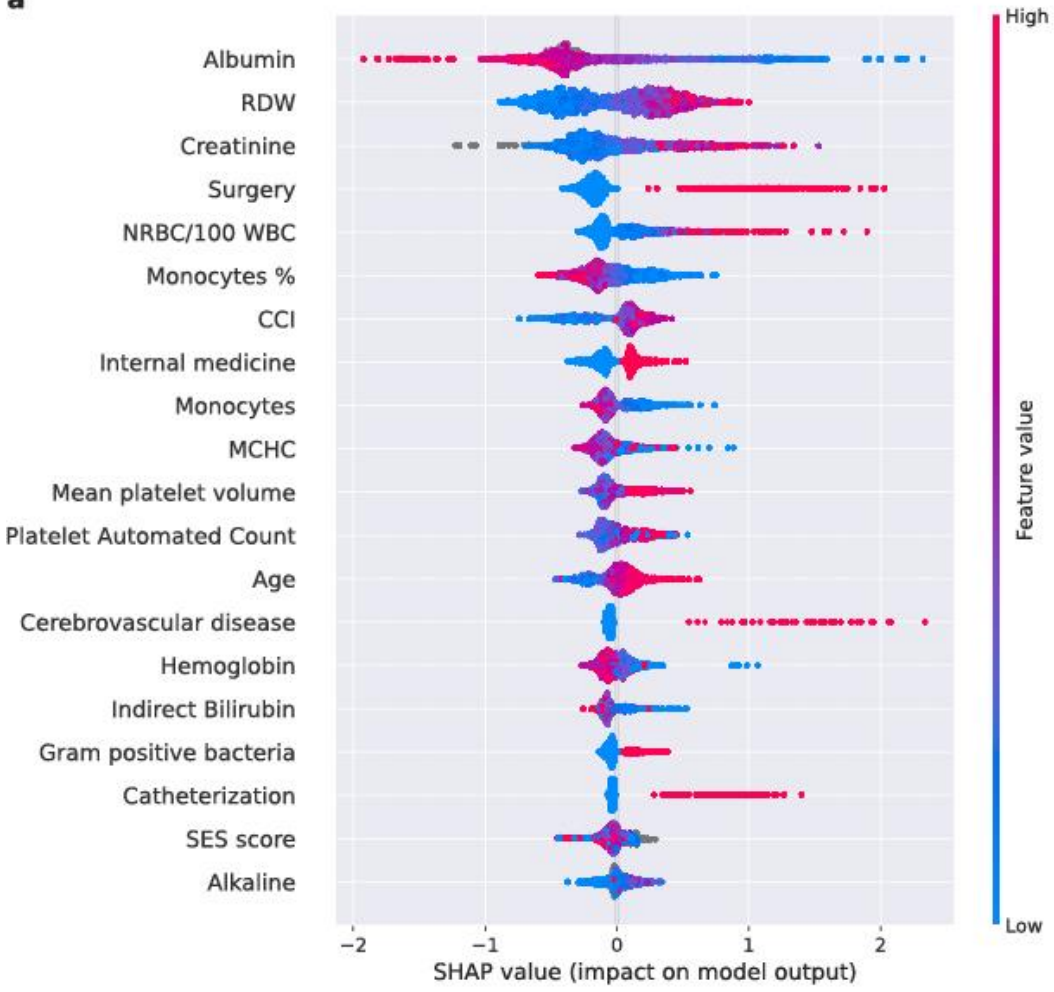

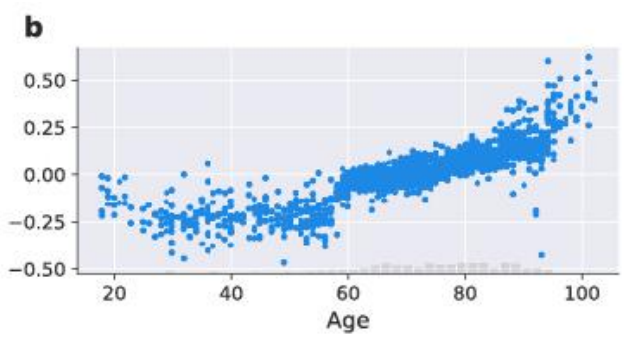

c

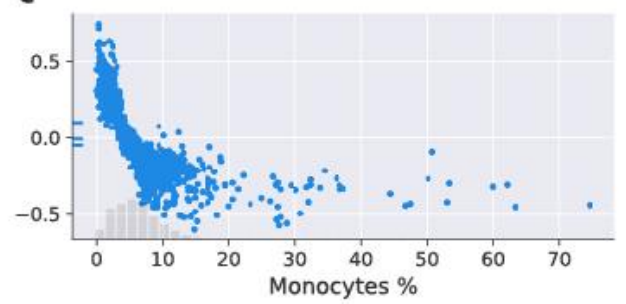

d

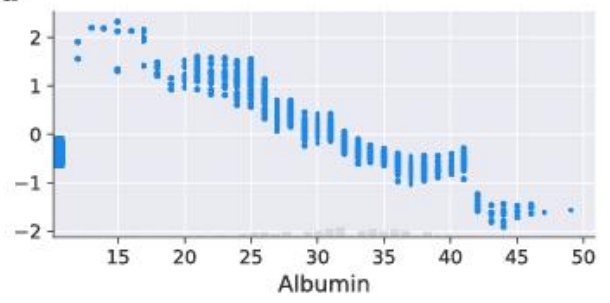

Figure 2: Feature analysis of the inclusive model a. A summary plot of the SHaply Additive exPlanations (SHAP) values for each feature. From top to bottom, the features are ordered by their overall influence on the final prediction (sum of SHAP values). In each feature (line), each point represents a specific case (individual), with colors ranging from red (high values of the predictor) to blue (low values of the predictor). Gray points signal missing values. A point's location on the X-axis represents the SHAP value - the effect the variable had on the prediction in a given individual; points further right indicate greater risk, and points to the left indicate lesser risk. The vertical line in the middle represents no change in risk. b A plot of SHAP for different values of age (years). The light histogram along the X-axis shows the density of the data. c A plot of SHAP for different values of monocytes percentage $(\%)$ in the blood. The light histogram along the X-axis shows the density of the data. d A plot of SHAP for different values of albumin $(\mathrm{g} / \mathrm{L})$. The light histogram along the $\mathrm{x}$-axis shows the density of the data. a-d are based on the future test set, $n=1,455$ unique patients. 

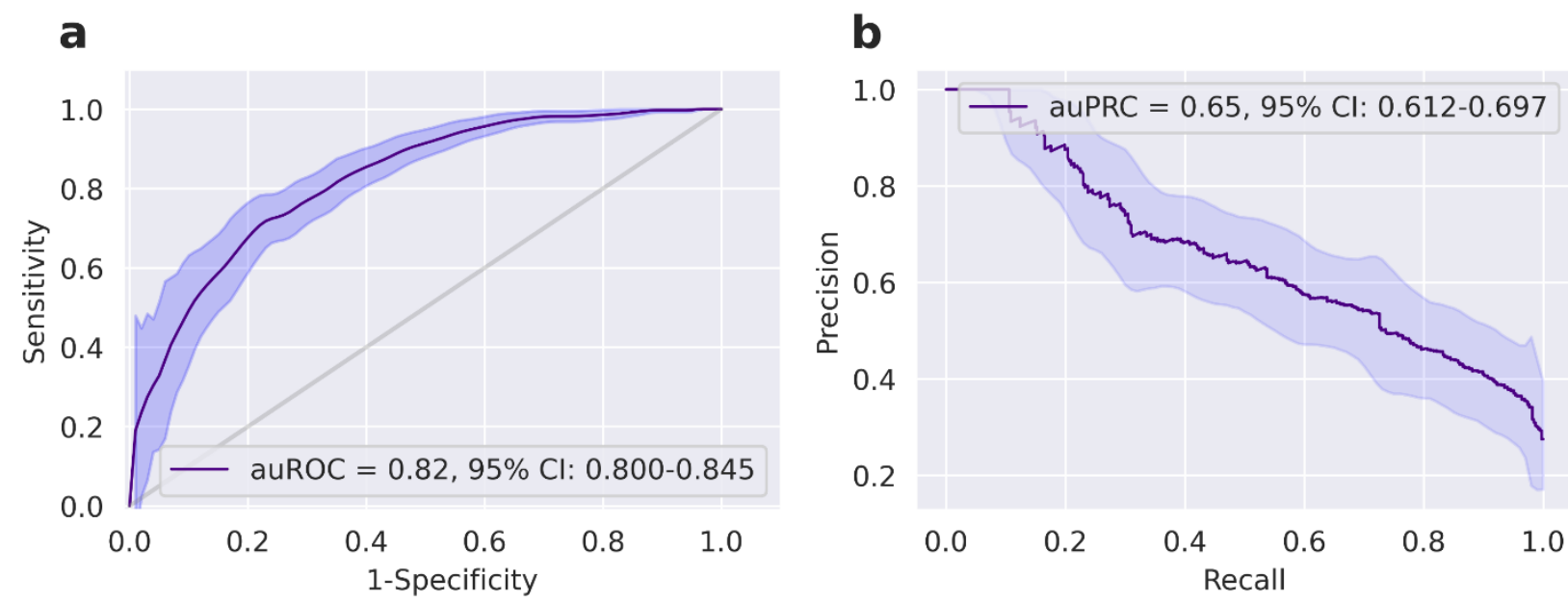

C

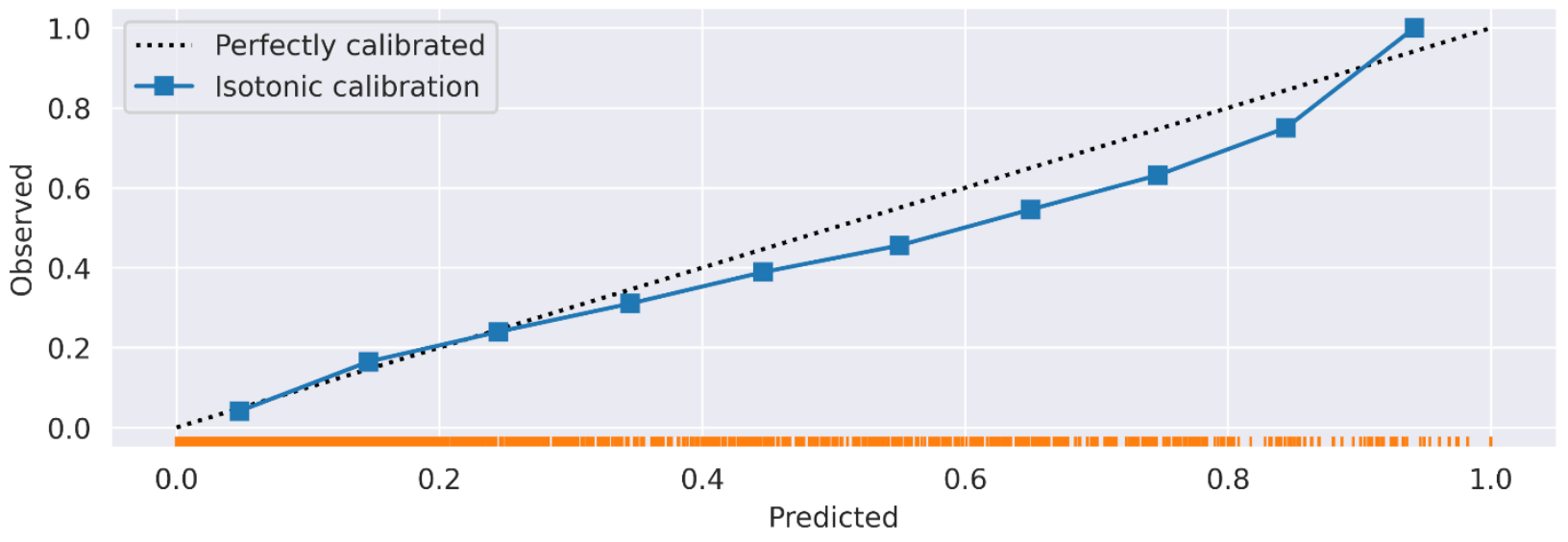

Figure 3: Performance of the inclusive model a. Receiver-operating characteristics (ROC) curves for predictions of the inclusive model on the prospective test set. The light band around the curve represents pointwise $95 \%$ confidence intervals derived by bootstrapping. b. A plot of the precision (positive predictive value, PPV) against the recall (sensitivity) of the predictor for different thresholds. The light band around the curve represents pointwise $95 \%$ confidence intervals derived by bootstrapping. c. Calibration plot, plotting the observed outcome against the predicted probabilities. The diagonal gray line represents perfect calibration. A smoothed line is fit to the curve, and points are drawn to represent the averages in ten discretized bins. The rug under the plot illustrates the distribution of predictions. 
medRxiv preprint doi: https://doi.org/10.1101/2021.05.18.21257369; this version posted May 19, 2021. The copyright holder for this preprint (which was not certified by peer review) is the author/funder, who has granted medRxiv a license to display the preprint in perpetuity.

It is made available under a CC-BY-NC-ND 4.0 International license .

a

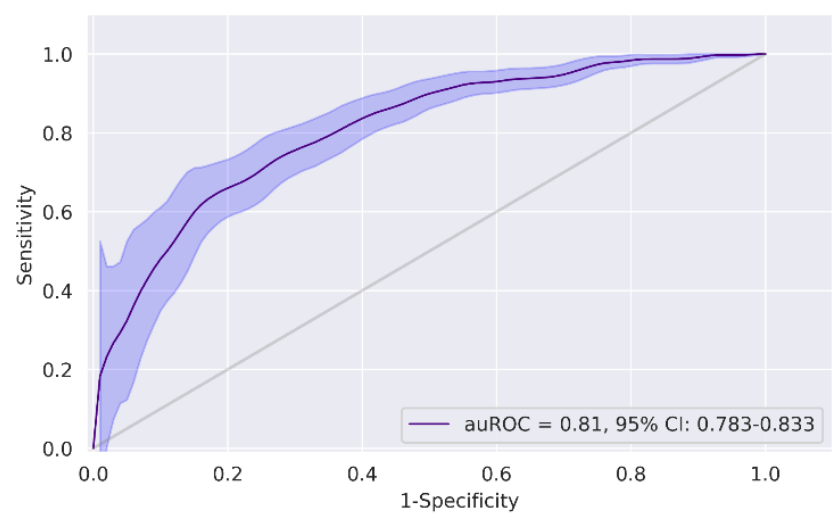

C

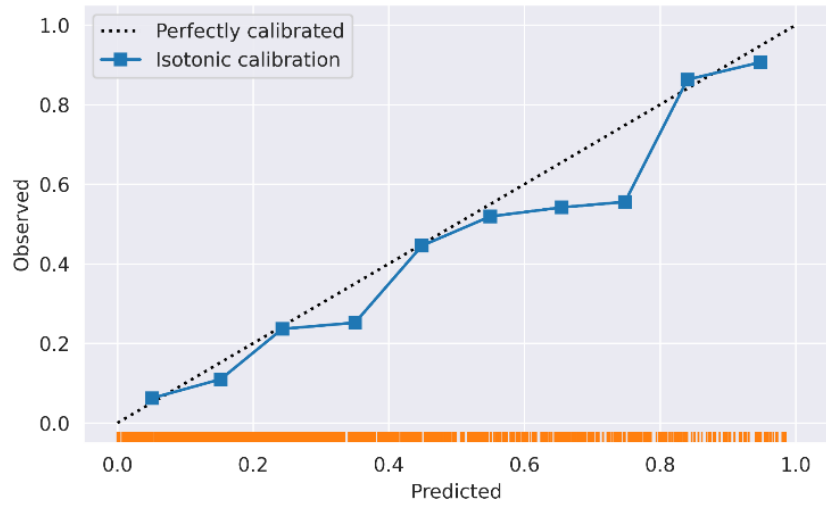

b

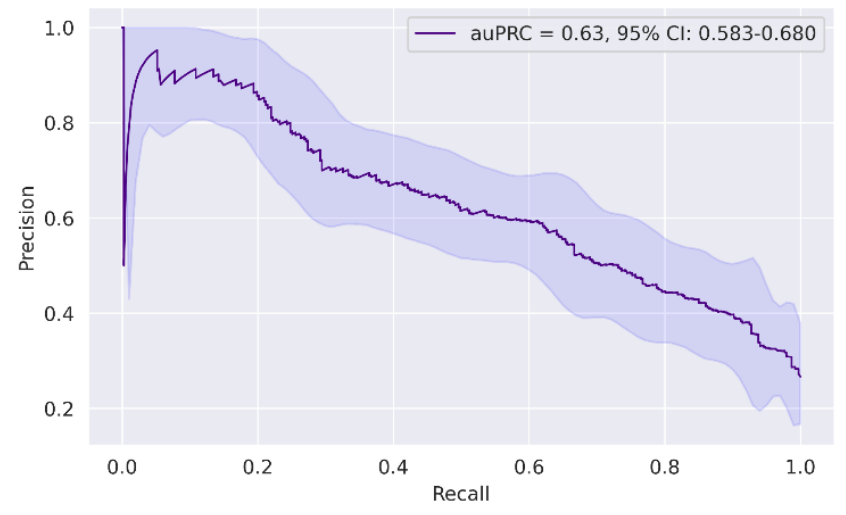

d
14) Albumin

15) Creatinine

16) Surgery

17) Mean platelet volume

18) HCT

19) Indirect Bilirubin

20) Alkaline

21) MCV

22) Respiratory diseases

23) ALT

24) Lymphocytes

25) Infectious background

Figure 4: Performance of the compact model a. Receiver-operating characteristics (ROC) curves for predictions of the compact model on the prospective test set. The light band around the curve represents pointwise $95 \%$ confidence intervals derived by bootstrapping. $\mathbf{b}$. A plot of the precision (positive predictive value, PPV) against the recall (sensitivity) of the predictor for different thresholds. The light band around the curve represents pointwise $95 \%$ confidence intervals derived by bootstrapping. c. Calibration plot, plotting the observed outcome against the predicted probabilities. The diagonal gray line represents perfect calibration. A smoothed line is fit to the curve, and points are drawn to represent the averages in ten discretized bins. The rug under the plot illustrates the distribution of predictions. d. All 25 features used by the compact model. 


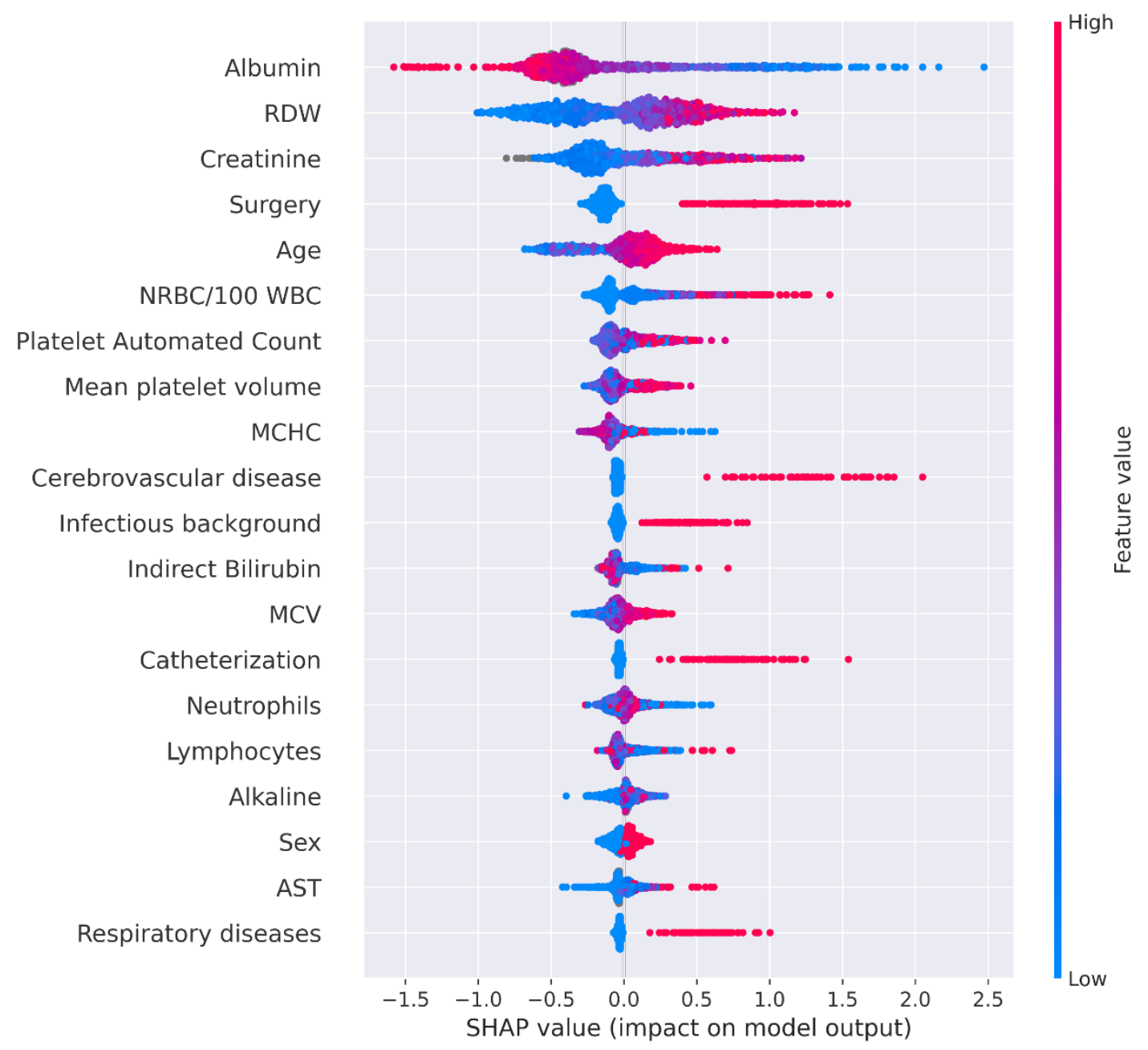

Figure 5: A summary plot of the SHAP values for each feature of the compact model. From top to bottom, features are ordered by their overall influence on the final prediction (sum of SHAP values). In each feature (line), each point represents a specific case (individual), with colors ranging from red (high values of the predictor) to blue (low values of the predictor). Gray points signal missing values. A point's location on the X-axis represents the SHAP value - the effect the variable had on the prediction in a given individual. The points further to the right indicate that for the given individual, the covariate contributed to increasing the risk. Points to the left indicate that the covariate contributed to decreasing the risk. The vertical line in the middle represents no change in risk. Values for the feature 'Sex' are 0 for female, and 1 for male. 
medRxiv preprint doi: https://doi.org/10.1101/2021.05.18.21257369; this version posted May 19, 2021. The copyright holder for this preprint (which was not certified by peer review) is the author/funder, who has granted medRxiv a license to display the preprint in perpetuity.

It is made available under a CC-BY-NC-ND 4.0 International license .

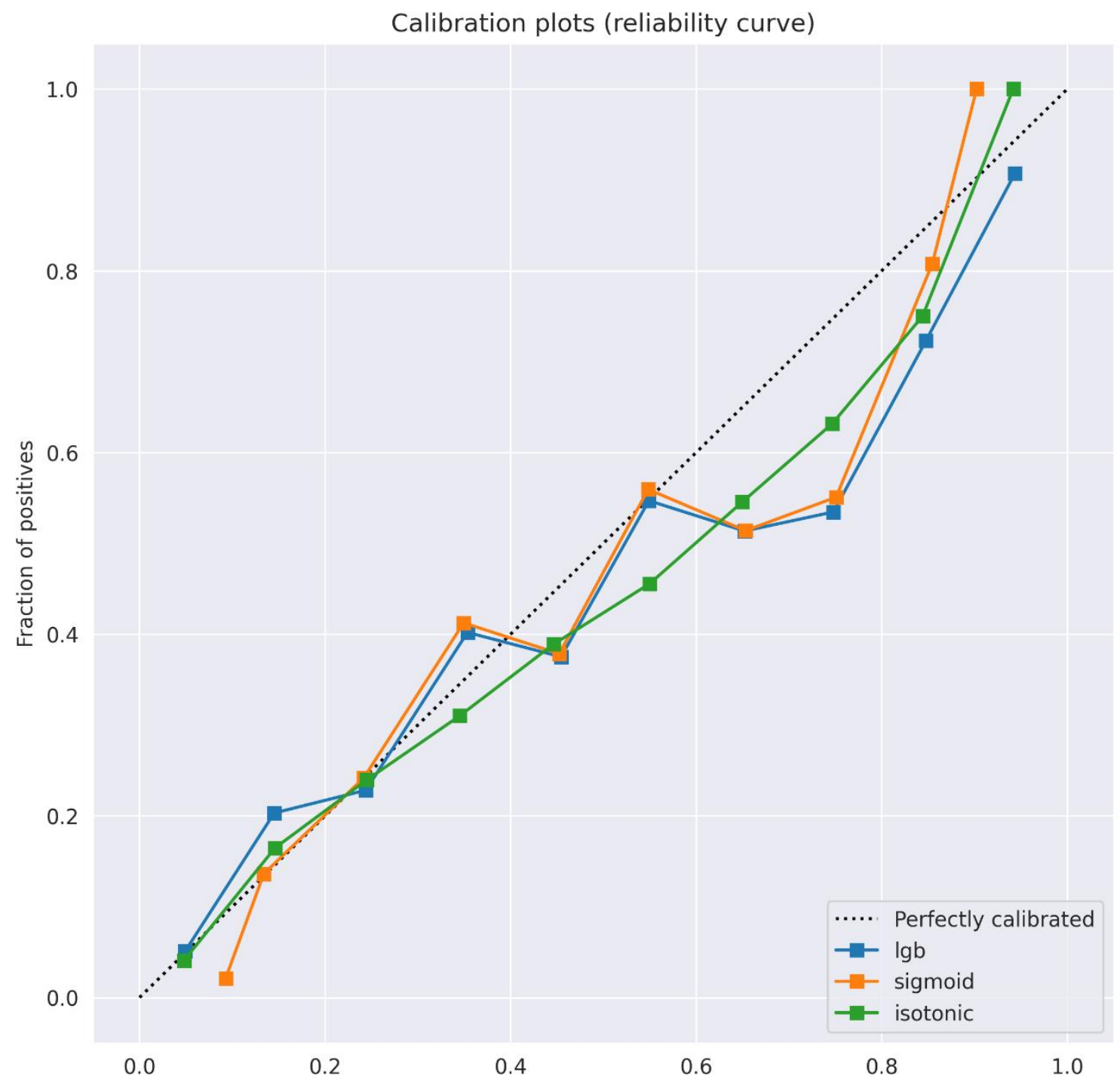

Figure 6. Calibration plots of the observed outcome against the predicted probabilities. The diagonal gray line represents perfect calibration. A smoothed line is fit to the curve, and points are drawn to represent the mean values in ten discretized bins. Blue, orange, and green lines correspond to the original uncalibrated model, the model after sigmoid calibration, and after isotonic calibration, respectively. 
medRxiv preprint doi: https://doi.org/10.1101/2021.05.18.21257369; this version posted May 19, 2021. The copyright holder for this preprint (which was not certified by peer review) is the author/funder, who has granted medRxiv a license to display the preprint in perpetuity. It is made available under a CC-BY-NC-ND 4.0 International license .

Tables

Table 1 Population Characteristics. CCI = Charlson Comorbidity Index

\begin{tabular}{|c|c|c|c|}
\hline & & Training set & Test set \\
\hline \multirow[t]{3}{*}{ General } & $\mathbf{N}$ & 6434 & 1455 \\
\hline & Age [median $( \pm)]$ & $74(24)$ & $73(22)$ \\
\hline & Females [\%] & 47.7 & 46.25 \\
\hline \multirow[t]{3}{*}{ CCI } & Mild [\%] & 20.66 & 20.03 \\
\hline & Moderate [\%] & 40.4 & 37.94 \\
\hline & Severe $[\%]$ & 38.94 & 42.03 \\
\hline \multirow[t]{3}{*}{ Admission type } & Elective [\%] & 5.08 & 5.54 \\
\hline & Emergency [\%] & 91.17 & 90.36 \\
\hline & Urgent [\%] & 3.75 & 4.1 \\
\hline \multirow[t]{2}{*}{ Other } & Infectious background [\%] & 9.71 & 9.42 \\
\hline & Surgery during hospital stay [\%] & 14.45 & 13.33 \\
\hline \multirow[t]{4}{*}{ Clinical outcomes } & Short-term mortality [\%] & 23.17 & 18.49 \\
\hline & Long hospital stay [\%] & 12.17 & 9.07 \\
\hline & Mechanical ventilation [\%] & 1.23 & 0.97 \\
\hline & Composite score [\%] & 34.24 & 26.6 \\
\hline
\end{tabular}

